\title{
Compared Evaluation of Botulinum Toxin A and a Cosmetic Antiperspirant in the Treatment of Focal Axillary Hyperhidrosis
}

\author{
Meike Streker, Stefanie Lübberding, Martina Kerscher \\ Cosmetic Science, Department of Chemistry, University of Hamburg, Hamburg, Germany. \\ Email: meike.streker@chemie.uni-hamburg.de \\ Received March 27 $7^{\text {th }}, 2013$; revised April 30 ${ }^{\text {th }}, 2013$; accepted May $8^{\text {th }}, 2013$
}

Copyright (C) 2013 Meike Streker et al. This is an open access article distributed under the Creative Commons Attribution License, which permits unrestricted use, distribution, and reproduction in any medium, provided the original work is properly cited.

\begin{abstract}
Background: Primary focal hyperhidrosis can significantly reduce quality of life. Therefore a lot of treatment options in a range of conservative, physical and surgical techniques are available. Objective: To assess the efficacy of an antiperspirant containing aluminum chloride compared to a Botulinumtoxin A treatment for patients with primary focal hyperhidrosis. Methods and material: In this randomized, single-center, half-side trail, a clinical score was done by patients and physician to evaluate the severity of hyperhidrosis. Gravimetric tests were performed to gather the amount of sweat per unit of time. Furthermore the efficacy was determined using a four point questionnaire. Skin irritation was assessed by measuring $\mathrm{pH}$ value and transepidermal water loss. Results: A total of 22 patients were enrolled. Two weeks after baseline the hyperhidrosis level was significantly reduced (BTX-A: $-92.9 \%$, AL: 66.7\%). In addition both treatment options induced a significant reduction of sweat production (BTX-A: $-80.8 \%$, AL: 68.8\%). Please change in: Patients evaluated good resp, very good efficacy for both treatment options at day 28. pH value and TEWL never left physiological range. Conclusion: Both botulinum toxin A treatment and an antiperspirant containing aluminum chloride in the evaluated galenic formulation are an effective and safe treatment option for axillary focal hyperhidrosis.
\end{abstract}

Keywords: Hyperhidrosis; Aluminum Chloride; Botulinum Toxin; Antiperspirant; Sweating

\section{Background}

Primary focal hyperhidrosis is a disorder of excessive eccrine sweating that mainly affects the axillae, palmae and plantae. At least 3\% of the population is affected persuadably with a high number of unreported cases due to an associated social phobia $[1,2]$. According to a study by Strutton et al., both axillary and palmar hyperhidrosis have the earliest average age of onset between 13 and 19 years [3]. The mean peak differs between 18 and 54 years. A genetic disposition is assumed, due to a high percentage of positive family history.

Hyperhidrosis can lead to frustration, embarrassment, a low self-esteem and finally may rest in social withdrawal [4]. Patients who are affected by axillary hyperhidrosis must change their clothing several times a day or choose only dark clothing which sweat points are not as visible. In addition skin maceration and secondary skin diseases such as fungal infection are promoted and bacterial colonization particularly leads to an unpleasant odor that also can significantly reduce quality of life [5].
The treatment options for primary focal hyperhidrosis involve a range of conservative, physical and surgical techniques. Iontophoresis causes a blockage of the sweat duct in the stratum corneum by directing a mild electrical current. However long-term maintenance therapy is required to keep patients without symptoms [6,7]. Anticholinergic agents have substantial side effects such as dryness of mouth, constipation and blurring of vision $[8,9]$. Surgical therapeutic options like endoscopic sympathectomy are effective but have a main limitation in a great potential of side effect and in a high incidence of mild to severe compensatory hyperhidrosis [10].

Due to the limitation of the mentioned therapeutic options, the treatment of primary focal hyperhidrosis with aluminum chloride or botulinum toxin $\mathrm{A}$ is the most popularly therapeutic option. Both efficacies are proven in several studies and the basic mechanism of actions has been established [11-16].

Aluminum chloride in concentrations of $12.5 \%$ to $25 \%$ reduces sweating by occluding the ducts of the eccrine 
sweat glands $[11,13]$. They diffuse into the sweat duct and form complexes with mucopolysaccharides and metal ions. Compared with the nocturnal activity of eccrine sweat glands antiperspirants including aluminum chloride have to apply at night. In some cases the application of aluminum chloride must be discontinued because of skin irritations.

Intradermal injections of botulinum toxin A reversibly block autonomic cholinergic nerve fibres. Acetylcholine is no longer released and the sweat glands chemically denervated [16]. Earlier studies have shown the efficacy in reducing sweat production. In addition, since there is a successful treatment of focal hyperhidrosis with botulinum toxin $\mathrm{A}$ in a few case reports, chemodenervation has emerged as a safe and effective treatment in several clinical trials [17-20]. Because of disappearing after 6 month, this treatment option is costly intensive.

The aim of the study was to compare a single treatment of botulinum toxin A with topical treatments of an antiperspirant, including aluminum chloride in a low dose formation for patients with primary focal hyperhidrosis using clinical scores and biophysical measurements.

\section{Methods}

\subsection{Patients}

This randomized, single-center half-side trail was conducted between March and September 2011. It was approved by the local ethical committee of Hamburg, Germany. Patients with primary focal hyperhidrosis on basis of the history questionnaire according to Bechara and of sweat production greater than $50 \mathrm{mg}$ per minute were included [21]. Moreover subjects who have not used antiperspirant, iontophoresis in the last 6 month or had been treated with botulinum toxin $\mathrm{A}$ in the last 12 month were selected. Patients had to understand the requirements of the study and sign an informed consent form. Skin diseases such as atopic dermatitis or fungal infections in the treatment area or known intolerability of aluminum salts were represented exclusion criteria. In total we enrolled 22 female patients aged 32 to 60 years.

\subsection{Study Design and Measurements}

After enrollment, patients received therapy with $12.5 \%$ aluminum chloride (Sweat-Off ${ }^{\circledR}$, Sweat-off GmbH, Hügelsheim, Germany) on one side and $50 \mathrm{U}$ of onabotulinumtoxin A. on the contralateral side following a randomization plan.

For the first two weeks the patients were asked to use the topical antiperspirant every evening. After reduce of the sweat production the patients have to apply the preparation according to the sweating.

For each patient one vial of onabotulinumtoxin A
(BTX-A) was prepared according to the randomization plan. One vial contained $100 \mathrm{U}$ powders for solution which was reconstituted with $4.0 \mathrm{ml}$ sterile physiological $(0.9 \%)$ sodium chloride solution. After cleaning the treating area local anesthetic was applied before injection. All patients received $50 \mathrm{U}$ of onabotulinumtoxin A into 10 to 15 intradermal injection points in an even distribution within the hyperhidrotic area which were previously defined by Minor's iodine-starch test.

The severity of hyperhidrosis was determined using a clinical score by Wörle et al. [21]. This was performed by investigator and patients themselves.

Gravimetric measurements were performed to evaluate the amount of sweat per unit of time. After an acclimation time of $30 \mathrm{~min}$ the amount of sweat was absorbed by filter paper (Melitta, Minden, Germany) and subsequently weighed using an ultra-fine scale.

In addition a four point subject questionnaire was performed to evaluate the efficacy; following the points: no efficacy, minimal efficacy, good efficacy and very good efficacy.

To evaluate the tolerability of the treatments, the $\mathrm{pH}$ value was measured using a combination electrode with the measurement and reference electrodes integrated in a single probe with measurement of potential using electrodes made of silver chloride or mercuric wire (Skin $\mathrm{pH}$ Meter PH 900, Courage and Khazaka, Cologne, Germany). In addition the transepidermal water loss (TEWL) was measured by using a condenser-chamber method (Aqua Flux Model AF200, London, UK) to evaluate the effects of aluminum chloride and botulinum toxin $\mathrm{A}$ of the skin barrier.

All measurements were performed at baseline, at day 14 , at day 28, at day 84 and at day 168 after first treatment (Table 1). Statistical analyses were performed with SPSS $^{\circledR}$. The data were analyzed using the KolmogorovSmirnow test and the paired t-test. Values of $\mathrm{p} \leq 0.05$ were considered significant.

\section{Results}

Data from 22 patients (mean age MV $47.8 \pm 5.7$ ) where was eligible. Baseline characteristics like age, weight and bodymass-index were not associated with sweat production.

Both injection with $50 \mathrm{U}$ onabotulinumtoxin $\mathrm{A}$ and the treatment with an antiperspirant containing aluminum chloride induced a significant reduction of sweat secretion (Figure 1). At visit 2, 14 days after treatment resp. after starting treatment the hyperhidrosis level decreased treatment $-92.9 \%$, after topical aluminum chloride $-66.7 \%$. At visit 3, 28 days the reduction in both therapeutic options was significant (BTX-A $-100 \%$; AL 
Table 1. Study overview.

\begin{tabular}{|c|c|c|c|c|c|c|c|c|c|c|}
\hline & Baseline & V1 0 & $1-13$ & V2 14 & $15-27$ & V3 28 & $29-84$ & V4 84 & $85-167$ & V5 168 \\
\hline enrollment & $\mathrm{X}$ & - & - & - & - & - & - & - & - & - \\
\hline injection & - & $\mathrm{X}$ & - & - & - & - & - & - & - & - \\
\hline acclimazation of $30 \mathrm{~min}$ & $\mathrm{X}$ & $\mathrm{X}$ & - & $\mathrm{X}$ & - & $\mathrm{X}$ & - & $\mathrm{X}$ & - & $\mathrm{X}$ \\
\hline apply of antiperspirant & - & $\mathrm{X}$ & $\mathrm{X}$ & - & $\mathrm{X}$ & - & $\mathrm{X}$ & - & $\mathrm{X}$ & - \\
\hline gravimetric measurements & $\mathrm{X}$ & $\mathrm{X}$ & - & $\mathrm{X}$ & - & $\mathrm{X}$ & - & $\mathrm{X}$ & - & $\mathrm{X}$ \\
\hline clinical score & - & $\mathrm{X}$ & - & $\mathrm{X}$ & - & $\mathrm{X}$ & - & $\mathrm{X}$ & - & $\mathrm{X}$ \\
\hline $\mathrm{pH}$-value & - & $\mathrm{X}$ & - & $\mathrm{X}$ & - & $X$ & - & $X$ & - & $\mathrm{X}$ \\
\hline TEWL & - & $X$ & - & $X$ & - & $X$ & - & $\mathrm{X}$ & - & $\mathrm{X}$ \\
\hline
\end{tabular}

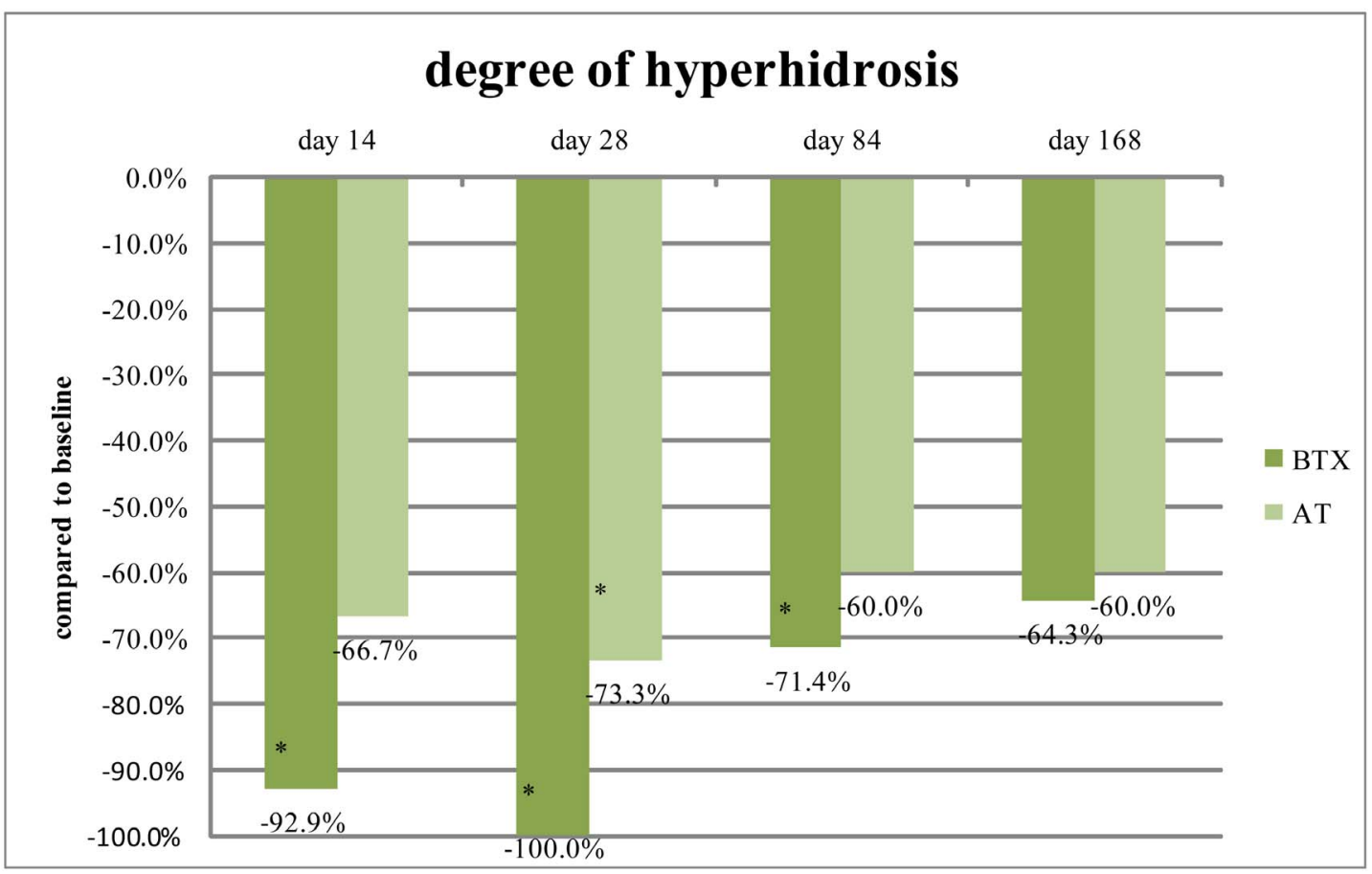

Figure 1. Degree of hyperhidrosis compared to baseline $(\mathrm{p}<\mathbf{0 . 0 5})$.

$-73.3 \% ; \mathrm{p} \leq 0.05) .6$ months after injection the BTX-A treated side was till significant reduced. Furthermore the aluminum chloride treated side was also still decreased.

The mean rates of sweat production at baseline were $165 \mathrm{mg} / 5 \mathrm{~min}$ in the axillae assigned to the treatment with botulinum toxin $\mathrm{A}$ and $184 \mathrm{mg} / 5 \mathrm{~min}$ in the axillae assigned to the treatment with aluminum chloride. The sweat production of both sides decreased significantly over the whole study period (Figure 2). Two weeks after initial treatment, the mean rates of sweat production were $31 \mathrm{mg} / 5 \mathrm{~min}$ in the axillae treated with botulinum toxin $\mathrm{A}$ and $57 \mathrm{mg} / 5 \mathrm{~min}$ in the axillae treated with aluminum chloride (BTX-A -80.8\%; AL -68.8\%; p < 0.05). 168 days after baseline the sweat production were $65 \mathrm{mg} / 5$ min in the axillae treated with BTX-A and $57 \mathrm{mg} / 5 \mathrm{~min}$ in the aluminum chloride treated side (BTX-A $-60.4 \%$; AL -68.9\%; $\mathrm{p}<0.05)$.

Patients evaluated for both products 28 days after baseline good efficacy resp. very good efficacy. 6 months after baseline patients rated the BTX-A treated side between minimal to good efficacy and the antiperspirant treated side as minimal efficacy (Figure 3).

The evaluation of skin surface $\mathrm{pH}$ revealed a reduction for both test products at all follow-up visits. During the use of the antiperspirant the $\mathrm{pH}$-value decreased for $13 \%$. After injection of BTX-A the $\mathrm{pH}$-value decreased for $7 \%$, 6 months after baseline (Figure 4). Both reductions were not statistically significant. 


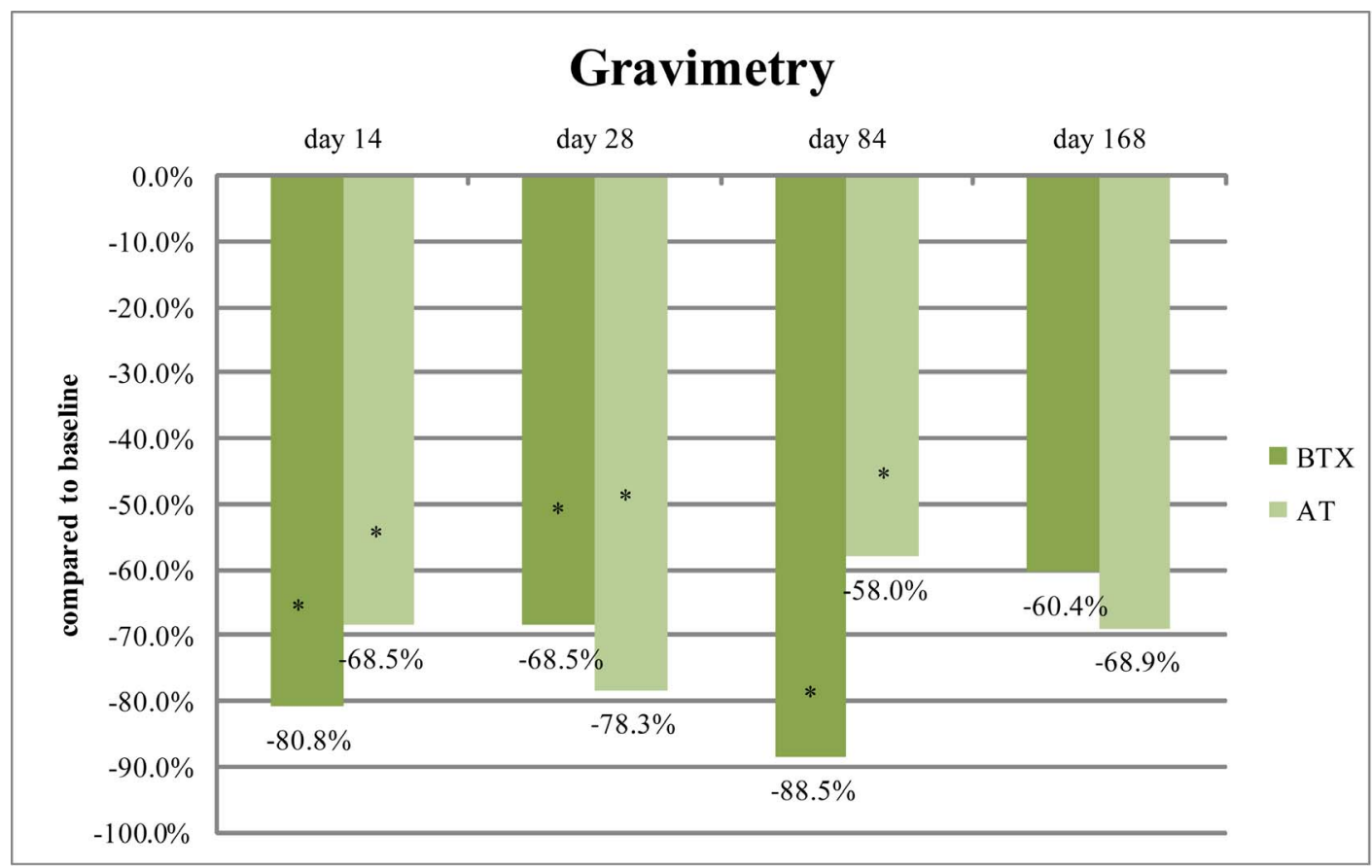

Figure 2. Gravimetric values compared to baseline $(\mathrm{p}<0.05)$.

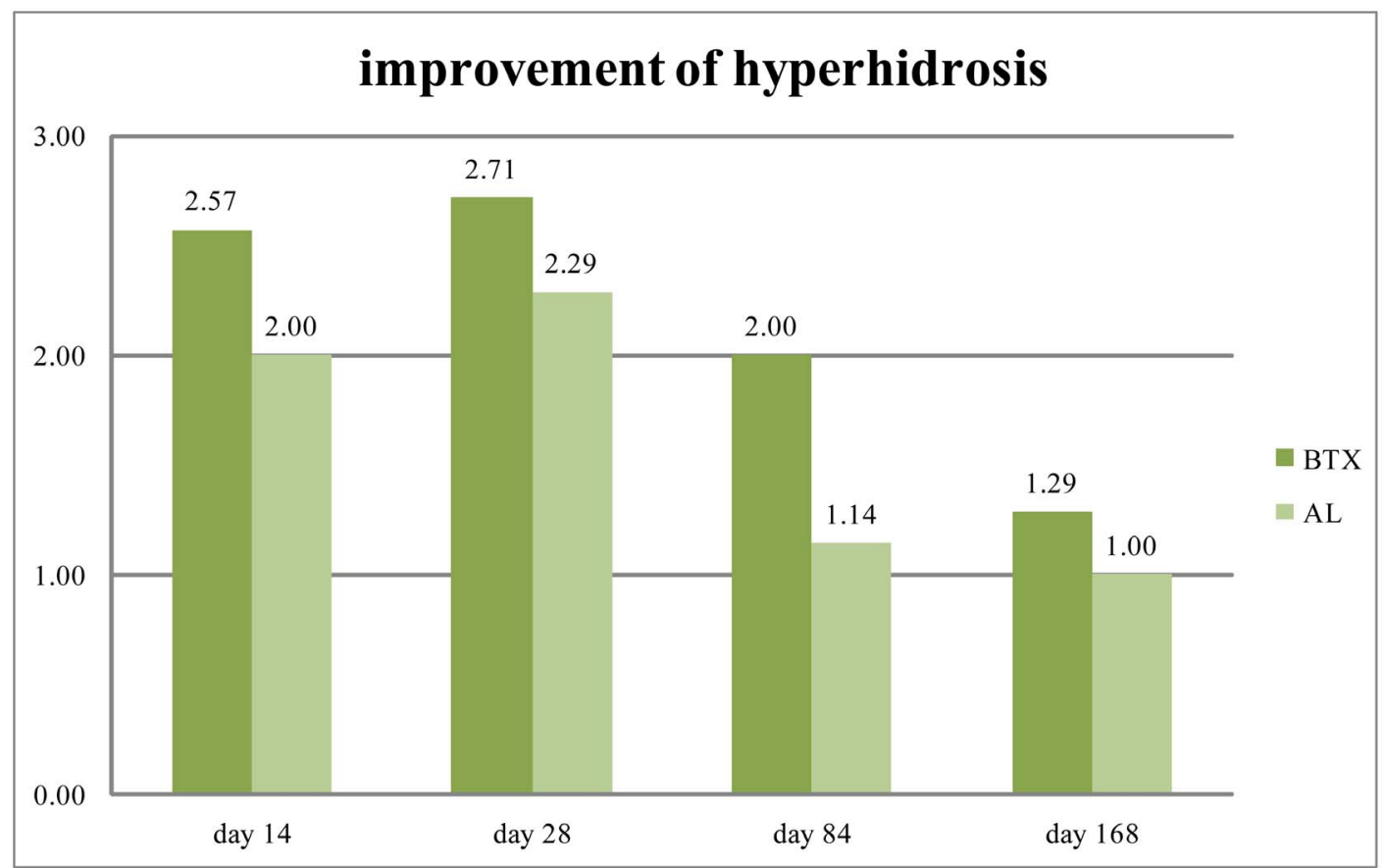

Figure 3. Improvement of hyperhidrosis; 0 = no efficacy; 1 = minimal efficacy; 2 = good efficacy; 3 = very good efficacy.

The TEWL values increased in the axillae assigned to the treatment with BTX-A over the study period. The mean increase in the TEWL value two weeks after baseline with BTX-A was $46.7 \%$, after starting treatment with aluminum chloride it was $12.8 \%$. 84 days after baseline the increase in the BTX-A treated side was $-32.7 \%$.
The axillae assigned to the aluminum chloride treated side increased by $12.3 \%$. At the last follow-up visit, 168 days after baseline the values after treatment with BTXA were decreased by $28.9 \%$. The TEWL values after treatment with aluminum chloride increased by $53.1 \%$ (Figure 5). 


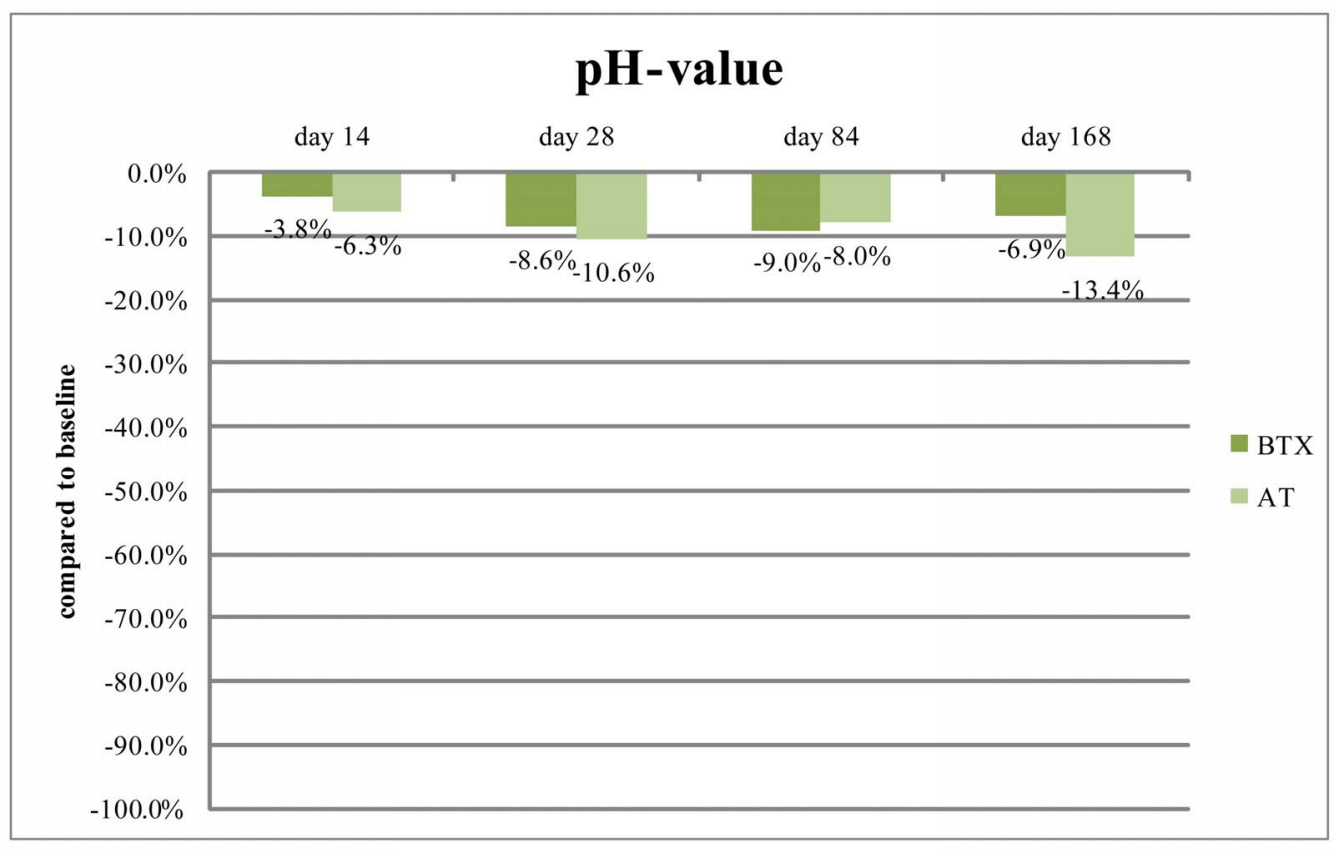

Figure 4. pH value compared to baseline.

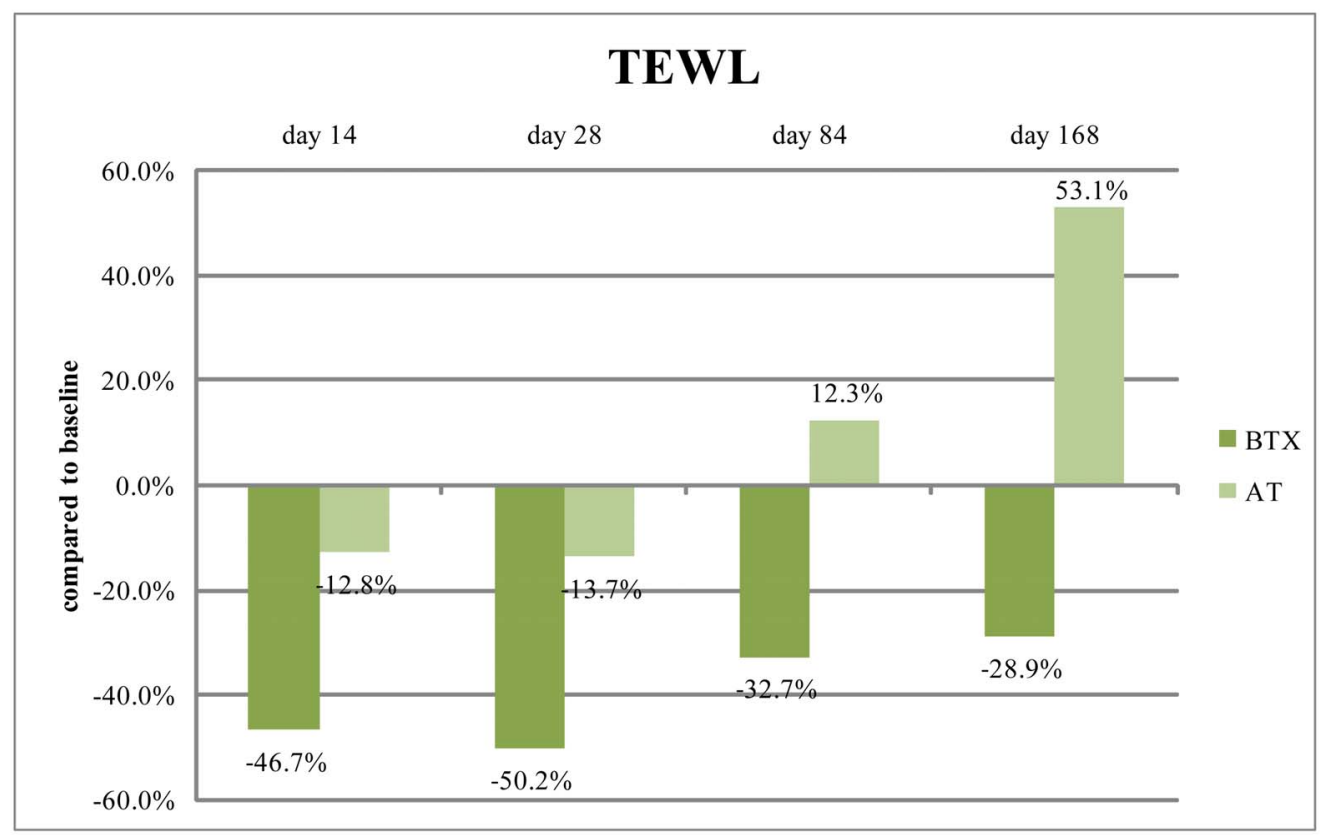

Figure 5. Transepidermal water loss compared to baseline.

During the whole study period there were no major adverse events. 6 patients recorded a mild to moderate irritation in skin after die first to third applications of the antiperspirant. There were no adverse events associated with the treatment with botulinum toxin $\mathrm{A}$.

\section{Discussion}

Hyperhidrosis is a common pathological condition which can have a profound effect on patient's behavior. Excessive sweating can inhibit social life and therefore decrease patient's quality of life. Further, an excessive sweating can induce skin maceration and causes seconddary microbial infections. Treating primary focal hyperhidrosis with aluminum chloride often is the first treatment therapy option in dermatology. Major limitations of aluminum chloride are stinging sensations and burning 
after application. Moreover skin irritation can be a cumulative side effect of long-term treatment.

Another effective treatment modality is the intradermal injection of botulinum toxin A which has been studied in numerous clinical trials [15,17-20]. It has demonstrated a sustained relief of symptoms with a good safety profile in open-label studies of the treatment of axillary hyperhidrosis. Naumann et al. demonstrated in a doubleblind, placebo-controlled trial a $93.8 \%$ response rate after a single treatment with $50 \mathrm{U}$ total onabotulinumtoxin $\mathrm{A}$ and a safety profile that was comparable to that of placebo injections [19]. In addition Heckmann et al. showed an efficacy of onabotulinumtoxin $\mathrm{A}$ in a placebo-controlled trial [15].

Therefore we designed an inter-individual comparison of onabotulinumtoxin $\mathrm{A}$ and a cosmetic antiperspirant containing aluminum chloride in a panel of 22 female patients suffering from hyperhidrosis as objected by gravimetry.

Regarding skin physiology both treatments were well tolerated. While TEWL decreased during both treatment modalities (BTX-A: 5.9 to 5.54; AL: 5.97 to 5.17), skin $\mathrm{pH}$ never left the physiological range.

Our study confirms and extends the results of previous studies regarding the gravimetry, the rate of sweat production and the tolerability [15-17,20-24].

Further to a previous study which compared botulinum toxin A with a topical $20 \%$ aluminum chloride for the treatment of focal axillary hyperhidrosis our data confirm that both products provide efficacy treatment option although our data are different concerning the tolerability of the antiperspirant [25]. According to Flanagan et al. the aluminum chloride treatment was well tolerated and effective only in the minority of the patients. This might be due to the lower dose of $12,5 \%$ aluminum chloride. However, while Flanagan et al. demonstrated a clean superiority of onabotulinumtoxin A and a high risk for skin irritation after treatment with aluminum chloride, our data did not reveal any significant differences in efficacy and tolerability between both treatments. This might be due to the special developed of non-alcoholic galinic formation and the low aluminum chloride concentration of the Sweat-Off ${ }^{\circledR}$ lotion.

\section{Conclusion}

Treatments of axillary focal hyperhidrosis with BTX-A or an antiperspirant containing aluminum chloride in the evaluated galenic formulation and low dose concentration are effective and safe options. Both treatment modalities significantly reduced the degree of hyperhidrosis. Patients rated both options as an effective treatment. However, patients with sensitive skin treatments with onabotulinumtoxin A seem to have a better therapeutic in- dex while topical treatment with aluminum chloride demonstrates a better economic impact.

\section{REFERENCES}

[1] F. G. Bechara, Current Treatment of Focal Hyperhidrosis," Surgical Approaches Hautarzt, Vol. 60, No. 7, 2009, pp. 538-545. doi:10.1007/s00105-009-1717-1

[2] F. G. Bechara, T. Gambichler, A. Bader, M. Sand, P. Altmeyer and K. Hoffmann, "Assessment of Quality of Life in Patients with Primary Axillary Hyperhidrosis Before and After Suction-Curettage," Journal of the American Academy of Dermatology, Vol. 57, No. 2, 2007, pp. 207-212. doi:10.1016/j.jaad.2007.01.035

[3] D. R. Strutton, J. W. Kowalski, D. A. Glaser and P. E. Stang, "US Prevalence of Hyperhidrosis and Impact on Individuals with Axillary Hyperhidrosis: Results from a National Survey," Journal of the American Academy of Dermatology, Vol. 51, No. 2, 2004, pp. 241-248. doi:10.1016/i.jaad.2003.12.040

[4] R. Ramos and J. Moya, "Primary Hyperhidrosis and Anxiety: A Prospective Preoperative Survey of 158 Patients," Archivos de Bronconeumología, Vol. 41, No. 2, 2005, pp. 88-92.

[5] M. Amir, A. Arish and Y. Weinstein, "Impairment in Quality of Life among Patients Seeking Surgery for Hyperhidrosis: Preliminary Results," Israel Journal of Psychiatry \& Related Sciences, Vol. 37, No. 1, 2000, pp. 25-31.

[6] W. B. Shelley and H. J. Hurley Jr., "Studies on Topical Antiperspirant Control of Axillary Hyperhidrosis," Acta Dermato-Venereologica, Vol. 55, No. 4, 1975, pp. 241260.

[7] H. Bouman, "The Treatment of Hyperhidrosis of Hands and Feet with Constant Current," American Journal of Physical Medicine \& Rehabilitation, Vol. 31, No. 3, 1952, pp. 158-169.

[8] B. Przybilla, U. Schwab, E. Hölzle and J. Ring, "Contact Sensitization to an Antiperspirant with the Active Ingredient Propantheline Bromide," Hautarzt, Vol. 34, No. 9, 1983, pp. 459-462.

[9] M. Hund, R. Sinkgraven and B. Rzany, "Randomized, Placebo-Controlled, Double Blind Clinical Trial for the Evaluation of the Efficacy and Safety of Oral Methantheliniumbromide (Vagantin) in the Treatment of Focal Hyperhidrosis," Journal der Deutschen Dermatologischen Gesellschaft, Vol. 2, No. 5, 2004, pp. 343-349. doi:10.1046/j.1439-0353.2004.04765.x

[10] K. T. Moran and M. P. Brady, "Surgical Management of Primary Hyperhidrosis," British Journal of Surgery, Vol. 78, No. 3, 1991, pp. 279-283. doi:10.1002/bjs.1800780306

[11] E. Hölzle and O. Braun-Falco, "Structural Alteractions of Axillary Eccrine Glands in Hyperhidrosis Following LongTerm Treatment with Aluminium Chloride Hexahydrate," British Journal of Dermatology, Vol. 110, No. 4, 1984, pp. 399-403. doi:10.1111/j.1365-2133.1984.tb04653.x

[12] E. Hölzle, “Topical Pharmacological Treatment," Current 
Problems in Dermatology, Vol. 30, 2002, pp. 30-43. doi: $10.1159 / 000060693$

[13] M. Streker, T. Reuther, S. Verst and M. Kerscher, "Axillary Hyperhidrosis - Efficacy and Tolerability of an Aluminium Chloride Antiperspirant," Hautarzt, Vol. 61, No. 2, 2010, pp. 139-144. doi:10.1007/s00105-009-1841-y

[14] L. Baumann, A. Slezinger, M. Halem, J. Vujevich, L. K. Martin, L. Black and J. Bryde, "Pilot Study of the Safety and Efficacy of Myobloc ${ }^{\circledR}$ (Botulinum Toxin Type B) for Treatment of Axillary Hyperhidrosis," International Journal of Dermatology, Vol. 44, No. 5, 2005, pp. 418-424. doi:10.1111/j.1365-4632.2004.02531.x

[15] M. Heckmann, A. O. Ceballos-Baumann and G. Plewig, "Botulinum Toxin A for Axillary Hyperhidrosis (Excessive Sweating)," New England Journal of Medicine, Vol. 344, 2001, pp. 488-493. doi:10.1056/NEJM200102153440704

[16] B. Sommer and G. Sattler, "Botulinum Toxin in der Aesthetischen Medizin Blackwell Wissenschafts-Verlag," Wien, Berlin, 2001.

[17] N. J. Lowe, D. A. Glaser, N. Eadie, S. Daggett, J. W. Kowalski and P. Y. Lai, "North American Botox in Primary Axillary Hyperhidrosis Clinical Study Group. Botulinum Toxin Type A in the Treatment of Primary Axillary Hyperhidrosis: A 52-Week Multicenter Double-Blind, Randomized, Placebo-Controlled Study of Efficacy and Safety," Journal of the American Academy of Dermatology, Vol. 56, No. 4, 2007, pp. 604-611. doi:10.1016/i.jaad.2007.01.009

[18] D. Dressler, "Comparing Botox ${ }^{\circledR}$ and Xeomin ${ }^{\circledR}$ for Axillar Hyperhidrosis," Journal of Neural Transmission, Vol. 117, No. 3, 2010, pp. 317-319. doi:10.1007/s00702-010-0372-0

[19] M. Naumann and N. J. Lowe, "Botulinum Toxin Type A in the Treatment of Bilateral Primary Axillary Hyperhi- drosis: Randomised, Parallel Group, Double Blind, Placebo Controlled Trial," BMJ, Vol. 323, No. 15, 2001, pp. 596-599. doi:10.1136/bmj.323.7313.596

[20] K. O. Bushara, D. M. Park, J. C. Jones and H. S. Schutta, "Botulinum Toxin-A Possible New Treatment for Axillary Hyperhidrosis," Clinical and Experimental Dermatology, Vol. 21, No. 4, 1996, pp. 276-278. doi:10.1111/j.1365-2230.1996.tb00093.x

[21] B. Wörle, S. Rapprich and M. Heckmann, "Definition and Treatment of Primary Hyperhidrosis," Journal der Deutschen Dermatologischen Gesellschaft, Vol. 5, No. 7, 2007, pp. 625-628. doi:10.1111/j.1610-0387.2007.06409.x

[22] N. Skroza, N. Bernardini, G. La Torre, G. La Viola and C. Potenza, "Correlation between Dermatology Life Quality Index and Minor Test and Differences in Their Levels over Time in Patients with Axillary Hyperhidrosis Treated with Botulinum Toxin Type A," Acta Dermatovenerologica Croatica, Vol. 19, No. 1, 2011, pp. 16-20.

[23] M. Naumann, N. J. Lowe, C. J. Kumar, et al., "Botulinum Toxin Type A Is a Safe and Effective Treatment for Axillary Hyperhidrosis over 16 Months: A Prospective Study," Archives of Dermatology, Vol, 139, No. 6, 2003, pp. 731-736. doi:10.1001/archderm.139.6.731

[24] M. Heckmann and G. Plewig, "Hyperhidrosis Study Group. Low-Dose Efficacy of Botulinum Toxin A for Axillary Hyperhidrosis: A Randomised, Side-by-Side, Open-Label Study," Archives of Dermatology, Vol. 141, No. 10, 2001, pp. 1255-1259. doi:10.1001/archderm.141.10.1255

[25] K. H. Flanagan, R. King and D. A. Glaser, "Botulinum Toxin Type a Versus Topical 20\% Aluminum Chloride for the Treatment of Moderate to Severe Primary Focal Axillary Hyperhidrosis," Journal of Drugs in Dermatology, Vol. 7, No. 3, 2008, pp. 221-227. 